\title{
SOCS3 overexpression inhibits advanced glycation end product-induced EMT in proximal tubule epithelial cells
}

\author{
LIN YU ${ }^{1-3}$, YING ZHANG ${ }^{4}$, HUIMIN ZHANG $^{1-3}$ and YINGTAO LI ${ }^{1-3}$ \\ ${ }^{1}$ Department of Obstetrics, The Third Affiliated Hospital of Guangzhou Medical University; \\ ${ }^{2}$ Guangzhou Institute of Obstetrics and Gynecology; ${ }^{3}$ Key Laboratory of Major Diseases in Guangdong; \\ ${ }^{4}$ Department of Endocrinology, The Third Affiliated Hospital of Guangzhou Medical University, \\ Guangzhou, Guangdong 510150, P.R. China
}

Received July 22, 2015; Accepted September 6, 2016

DOI: $10.3892 / e t m .2017 .4297$

\begin{abstract}
Diabetic nephropathy (DN) is among the most severe complications of diabetes mellitus, and may lead to end-stage renal disease. Sustained exposure to advanced glycation end products (AGEs) typically causes renal tubular epithelial cells (TECs) to suffer from an epithelial-to-mesenchymal transition (EMT). However, there remains no consensus regarding the mechanism underlying the cause of EMT in TECs as induced by AGEs. In the present study, we investigated the promotion of EMT in TECs by AGEs, and the activation of Janus kinase/signal transducers and activators of transcription (JAK/STAT) signaling. In addition, we constructed a recombinant adenovirus (Ad) that overexpressed suppressor of cytokine signaling 3 (SOCS3), and examined the regulatory role of SOCS3 in the activation of JAK/STAT signaling and the promotion of EMT in TECs. The results demonstrated that AGE-bovine serum albumin (BSA) treatment significantly promoted the expression of EMT-associated proteins, while reducing the expression of the epithelial cell marker, E-cadherin. Furthermore, the Ad-mediated SOCS3 overexpression markedly inhibited the AGE-BSA-induced JAK2/STAT3 activation; phosphorylated JAK2 and phosphorylated STAT3 expression levels were reduced by the Ad-SOCS3 infection, compared with the control Ad (Ad-con) infection, in HK-2 cells subject to AGE-BSA. Moreover, the overexpression of SOCS3 markedly inhibited the AGE-BSA-promoted EMT in HK-2 cells. AGE-BSA-promoted EMT-associated proteins, such as $\alpha$-smooth muscle actin and collagen I, were reduced by the Ad-SOCS3 virus infection, in contrast to the Ad-con virus infection. Furthermore, reduced E-cadherin expression was reversed by the Ad-SOCS3 virus infection, in contrast to the Ad-con virus infection, in epithelial
\end{abstract}

Correspondence to: Dr Yingtao Li, Department of Obstetrics, The Third Affiliated Hospital of Guangzhou Medical University, 63 Duobao Road, Guangzhou, Guangdong 510150, P.R. China E-mail: yingtao828li@163.com

Key words: suppressor of cytokine signaling 3, advanced glycation end products, epithelial-to-mesenchymal transition, Janus kinase/signal transducers and activators of transcription
HK-2 cells. In conclusion, the present study confirmed the inhibitory role of SOCS3 in the AGE-induced EMT in renal TECs, implying the protective role of SOCS3 in DN.

\section{Introduction}

Diabetic nephropathy (DN) is among the most severe complications of diabetes mellitus (DM) (1), and may lead to end-stage renal disease (2). Without intervention, diabetic patients with microalbuminuria will typically progress to proteinuria and DN (3). However, little is known about the molecular pathogenesis of DN. The sustained hyperglycemia exerts histopathological injury to kidneys, and gradually results in functional loss of kidneys (3). Particularly, advanced glycation end products (AGEs), which develop via the Maillard reaction (4), predominantly in DM $(5,6)$, have been confirmed to promote diabetic microvascular complications in DM (7-9). AGEs have been reported to promote transcription factors such as nuclear factor kappa-light-chain-enhancer of activated

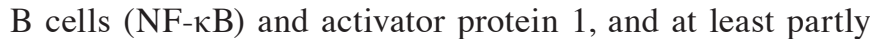
promote the apoptosis (10-12). Furthermore, sustained AGE exposure typically causes renal tubular epithelial cells (TECs) to suffer from an epithelial-to-mesenchymal transition (EMT), losing their epithelial phenotypes and acquiring mesenchymal, fibroblast-like properties $(13,14)$. However, there remains no consensus regarding the specific mechanism underlying the promotion of EMT in TECs by AGEs.

Previous animal model studies have confirmed the Janus kinase/signal transducer and activator of transcription (JAK/STAT) signaling is disordered in glomerular and tubulointerstitial cells in humans with DN (15). Elevated glucose $(16,17)$ or AGE $(18)$ levels may result in the activation of JAK2/STAT signaling in the renal cortex of rodents with early DN. Connective tissue growth factor (CTGF) and transforming growth factor beta (TGF- $\beta$ ) have been clinically and experimentally confirmed to correlate closely with the pathogenesis of DN (19-21), and have been shown to play key roles in the EMT of TECs in the early and reversible stage of renal interstitial fibrosis (RIF) $(22,23)$. Moreover, JAK2/STAT signaling has been reported to be involved in TGF- $\beta$ and CTGF expression (24). The induction of TGF- $\beta$ and fibronectin expression from JAK2/STAT signaling is abrogated by JAK2 
inhibition $(16,24)$. In addition, the regulation of CTGF expression has been indicated to depend on the JAK/STAT- $1 \alpha$ and $\mathrm{NF}-\kappa \mathrm{B}$ signaling pathways (25).

It has been demonstrated that there is a robust and apparently chronic increase in levels of suppressor of cytokine signaling 1 (SOCS1) and SOCS3 (26) in a DM rat model and patients with progressive DN. Both SOCS1 and SOCS3 inhibit JAK2 signaling (27). The overexpression of SOCS proteins has been observed in proximal tubular cells as well as in certain glomerular cells in human diabetic nephropathy (28). Ortiz-Munoz et al found that the upregulation of recombinant SOCS1 and SOCS3 in rats reduced JAK/STAT activation and somewhat ameliorated the very early diabetic changes (26). This result implies the protective role of SOCS proteins in DN. However, the specific mechanism underlying the potential protective role of SOCS in DN remains unclear.

In the present study, we investigated the promotion of EMT in TECs by AGEs and the activation of JAK/STAT signaling. Then we constructed a recombinant adenovirus that overexpressed SOCS3, and examined the regulatory role of SOCS3 in the activation of JAK/STAT signaling and the promotion of EMT in TECs.

\section{Materials and methods}

Cell culture, treatment and reagents. Human tubular epithelial HK-2 cells were purchased from American Type Culture Collection (Rockville, MD, USA) and were maintained in Dulbecco's Modified Eagle's Medium:Nutrient Mixture F-12 (DMEM/F-12; Invitrogen; Thermo Fisher Scientific, Inc., Waltham, MA, USA) containing $10 \%$ fetal calf serum (FBS; both Gibco; Thermo Fisher Scientific, Inc.), supplemented with $100 \mathrm{U} / 1$ penicillin and $10 \mathrm{mg} / 1$ streptomycin (CSPC Pharmaceutical Group Limited, Shijiazhuang, China). Cells were incubated in a humidified atmosphere containing $5 \% \mathrm{CO}_{2}$ at $37^{\circ} \mathrm{C}$ and propagated every five days at a split ratio of $1: 4$ using trypsin (Amresco, Framingham, MA, USA). For assessment of the effect of AGE-bovine serum albumin (BSA) on endothelial cells, $\sim 85 \%$ confluent HK-2 cells were incubated with F-12K medium containing $2 \% \mathrm{FBS}, 100$ or $300 \mu \mathrm{g} / \mathrm{ml} \mathrm{AGE-BSA}$ or BSA for 48 or $96 \mathrm{~h}$. Cells were then collected for mRNA or protein analysis. For the experiments to investigate the regulation by AGE-BSA on EMT, cells were analyzed by western blotting for E-cadherin, $\alpha$-SMA and collagen I, following the BSA or AGE-BSA treatment.

Preparation and characterization of AGEs-BSA. AGE-BSA was prepared using D-glucose (Sigma-Aldrich; Merck KGaA, Darmstadt, Germany) and bovine serum albumin (BSA; Thermo Fisher Scientific, Inc.) as previously described (29,30). In brief, $50 \mathrm{mg} / \mathrm{ml} \mathrm{BSA}$ was incubated with (Glu-BSA) or without (Control) 0.25 M D-glucose in 0.2 M phosphate-buffered saline (PBS; pH 7.4) at $37^{\circ} \mathrm{C}$ for 8 weeks in the dark, using $50 \mathrm{mg} / \mathrm{ml}$ BSA prepared by the same incubation without D-glucose as control. All preparations of AGEs and BSA control were dialyzed in $10 \mathrm{mM}$ PBS ( $\mathrm{pH}$ 7.4) for $96 \mathrm{~h}$ to remove the free glucose, and passed over Detoxigel columns (Detoxi-Gel Endotoxin Gel; Thermo Fisher Scientific, Inc.) to remove endotoxin. The protein concentration was determined using a bicinchoninic acid (BCA) protein assay kit (Thermo Fisher Scientific, Inc.). Glycation of
AGE-BSA was examined by spectrofluorometry (PerkinElmer, Inc., Waltham, MA, USA) at an excitation wavelength of $370 \mathrm{~nm}$ and emission wavelength of $440 \mathrm{~nm}$.

Reverse transcription-quantitative polymerase chain reaction $(R T-q P C R)$. Total cellular RNA from HK-2 cells was purified using TRIzol agent (Thermo Fisher Scientific, Inc.) according to the manufacturer's instructions and was supplemented with RNase inhibitor (Takara Bio, Inc., Tokyo, Japan). DNA-DNase Treatment \& Removal Reagent (Thermo Fisher Scientific Inc., Waltham, MA, USA) was utilized to remove genomic DNA. RT-qPCR was performed with Takara One Step RT-PCR kit (RR046A; Takara Bio, Inc.) with the primers and probes for E-cadherin (forward, 5'-GATGAA AATCTGAAAGCGG-3' and reverse, 5'-AACACGAGC AGAGAATCATA-3'; probe, 5'-FAM-ATACTGACCCCA CAGCCCC-BHQ-3') or for $\alpha$-SMA (forward, 5'-GACCCT GAAGTACCCGATA-3'and reverse, 5'-AGTGGTGCCAGA TCTTTTC-3'; probe, 5'-FAM-ATCATCACCAACTGG GACG-BHQ-3'; both Sangon Biotech, Shanghai, China). The reaction mix $(20 \mu \mathrm{l})$ was prepared as follows: 2X One Step RT-PCR Buffer III (10 $\mu$ ), TaKaRa Ex Taq HS (5 U/ $\mu$; $0.4 \mu 1)$, PrimeScript RT Enzyme Mix $(0.4 \mu 1)$, forward/reverse primer $(10 \mu \mathrm{M} ; 0.4 \mu \mathrm{l})$, probe $(0.8 \mu \mathrm{l})$, target RNA $(2 \mu \mathrm{l})$, RNase Free dH2O $(5.6 \mu \mathrm{l})$. The reaction was performed under the following conditions: For reverse transcription: $42^{\circ} \mathrm{C}$ for $5 \mathrm{~min}$ and $95^{\circ} \mathrm{C}$ for $10 \mathrm{sec}$ for one cycle; for PCR: $95^{\circ} \mathrm{C}$ for $5 \mathrm{sec}$ and $60^{\circ} \mathrm{C}$ for $20 \mathrm{sec}$ for 40 cycles. $\mathrm{dd}_{2} \mathrm{O}_{2}$ was utilized as a negative control and was subjected to the same reaction (without RNA sample). Relative quantification was determined using the $\Delta \Delta \mathrm{Cq}$ method using $\alpha$-tubulin (forward, 5'-ACTGGCACCTACCGCCAGCT-3' and reverse, 5'-GCA GCATCTTCCTTGCCTGT-3'; probe, 5'-FAM-TCTTCC ACCCTGAGCAGCTC-BHQ-3'; Sangon Biotech) as a reference gene (31). Each RT-qPCR reaction was independently performed in triplicate.

Western blotting assay. Protein samples from HK-2 cells were isolated using a cytoplasm extraction buffer and quantified using a BCA protein assay kit (Thermo Fisher Scientific, Inc.). Protein samples $(5 \mu \mathrm{g})$ were separated by $12 \%$ SDS-PAGE, transferred to PVDF membranes (Invitrogen; Thermo Fisher Scientific, Inc., Carlsbad, CA, USA) and blocked with $2 \%$ BSA at $4^{\circ} \mathrm{C}$ overnight. Target protein bands in the PVDF membranes were probed with rabbit polyclonal antibodies against E-cadherin (ab15148; 1:600), SOCS3 (ab16030; 1:500; both Abcam, Cambridge, UK), $\alpha$-smooth muscle actin ( $\alpha$-SMA; ab5694; 1:700; LifeSpan BioSciences, Inc., Seattle, WA, USA), collagen I (ab34710; 1:300; Abcam), unphosphorylated STAT3 (AP20339a; 1:800), STAT3 phosphorylated at Tyr705 (AP3261a; 1:500; both Abgent, San Diego, CA, USA), unphosphorylated JAK2 (ab98031; 1:1,000, JAK2 phosphorylated at Tyr1007 (ab195055; 1:1,000) and $\alpha$-tubulin (ab18251; 1:900; all Abcam). Primary antibody incubation was performed at $4^{\circ} \mathrm{C}$ for $2 \mathrm{~h}$. Following washing four times with PBS, the membranes were incubated with goat anti-rabbit IgG (ab150077; 1:1,000; Abcam) secondary antibody conjugated to horseradish peroxidase $(1: 1,000 ; \mathrm{ab} 6721$; Abcam) at room temperature for $45 \mathrm{~min}$ and an enhanced chemiluminescence detection system (Super Signal West Femto; Thermo Fisher 
A

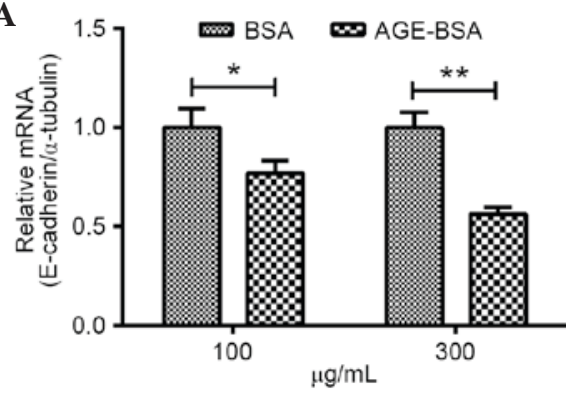

C $\quad B S A(\mu \mathrm{g} / \mathrm{mL}) \quad 100 \quad 300 \quad 0 \quad 0$

AGE-BSA $(\mu \mathrm{g} / \mathrm{mL}) \quad 0 \quad 0 \quad 100 \quad 300$

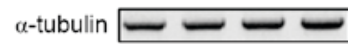

E-cadherin

$\alpha-S M A$

Coll

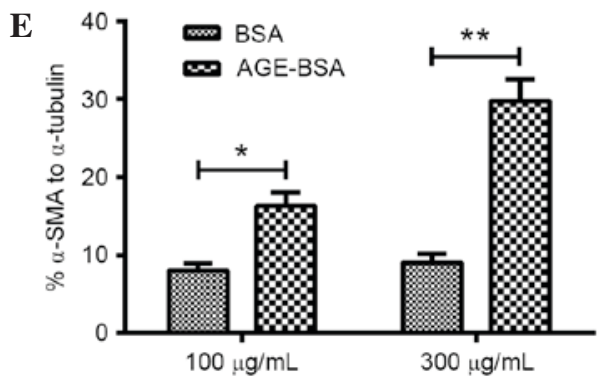

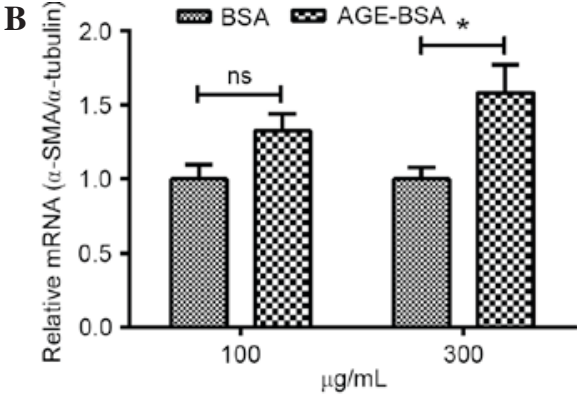

D
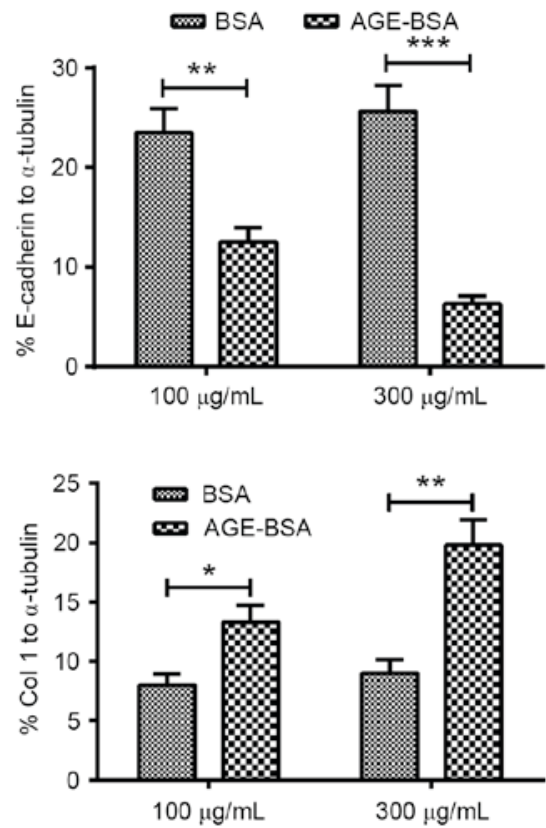

Figure 1. Analysis of transdifferentiation-associated markers in renal tubular epithelial HK-2 cells following AGE-BSA treatment. (A and B) Relative mRNA expression of (A) E-cadherin and (B) $\alpha$-SMA in HK-2 cells post-treatment with 100 or $300 \mu \mathrm{g} / \mathrm{ml}$ AGE-BSA or BSA for two days. (C) Western blot assay of E-cadherin, $\alpha$-SMA, collagen I and $\alpha$-tubulin in HK-2 cells which were treated with the 100 or $300 \mu \mathrm{g} / \mathrm{ml}$ AGE-BSA or BSA for four days. Percentage of (D) E-cadherin, (E) $\alpha$-SMA and (F) collagen I to $\alpha$-tubulin in HK-2 cells which were treated with the AGE-BSA or BSA. Data are presented as mean \pm standard error for three independent experiments. ${ }^{*} \mathrm{P}<0.05,{ }^{* *} \mathrm{P}<0.01$ and ${ }^{* * * *} \mathrm{P}<0.001$. BSA, bovine serum albumin; AGE, advance glycation end products; $\alpha$-SMA, alpha smooth muscle actin; ns, no significance.

Scientific, Inc.) was subsequently used for target protein detection.

Adenovirus-mediated overexpression of SOCS3 in $\mathrm{HK}-2$ cells. A recombinant adenovirus encoding human SOCS3 (Ad-SOCS3) was constructed and generated by Shanghai ShineGene Molecular Biotech, Inc. (Shanghai, China) as previously described (32) using a reverse genetic method. A recombinant adenovirus which encoded CAT gene (Ad-con) was used as a control. SOCS3 expression mRNA and protein expression was verified using RT-qPCR and western blot assay. HK-2 cells were infected with a multiplicity of infection (MOI) of 0,1 or 5 purified Ad-SOCS3 or Ad-con viruses.

Statistical analysis. Statistical significance was calculated using the GraphPad Prism 6 statistical software (GraphPad Software, Inc., La Jolla, CA, USA). The significance between two groups was examined using the unpaired Student $t$-test. The significance among three or more groups was examined using the analysis of variance test. $\mathrm{P}<0.05$ was considered to indicate a statistically significant difference.

\section{Results}

AGE-BSA induces EMT in renal tubular epithelial $H K-2$ cells. We initially investigated the EMT induction by AGEs in renal tubular epithelial HK-2 cells. As shown in Fig. 1A, the AGE-BSA treatment for $24 \mathrm{~h}$ significantly downregulated the mRNA expression of E-cadherin, which is the epithelial cell marker $(\mathrm{P}<0.05$ for $100 \mu \mathrm{g} / \mathrm{ml} ; \mathrm{P}<0.01$ for $300 \mu \mathrm{g} / \mathrm{ml}$; Fig. 1A), compared to the BSA with same concentration. By contrast, the mRNA expression of $\alpha$-SMA, which is the mesenchymal cell marker, was markedly upregulated $(\mathrm{P}<0.05$ for $300 \mu \mathrm{g} / \mathrm{ml}$; Fig. 1B). Then we analyzed the E-cadherin and EMT-associated protein expression using western blot assay (Fig. 1C). It was indicated that the E-cadherin was also significantly downregulated by the AGE-BSA treatment with 100 or $300 \mu \mathrm{g} / \mathrm{ml}$ for $48 \mathrm{~h}(\mathrm{P}<0.01$ or $\mathrm{P}<0.001$; Fig. 1D). By contrast, the protein levels of the mysenchymal markers $\alpha$-SMA and collagen I were significantly upregulated by the AGE-BSA $(\mathrm{P}<0.05$ for $100 \mu \mathrm{g} / \mathrm{ml}$; $\mathrm{P}<0.01$ for $300 \mu \mathrm{g} / \mathrm{ml}$; Fig. $1 \mathrm{E}$ and $\mathrm{F})$. Collectively, these results suggest that AGEs induced EMT in renal tubular epithelial HK-2 cells. 

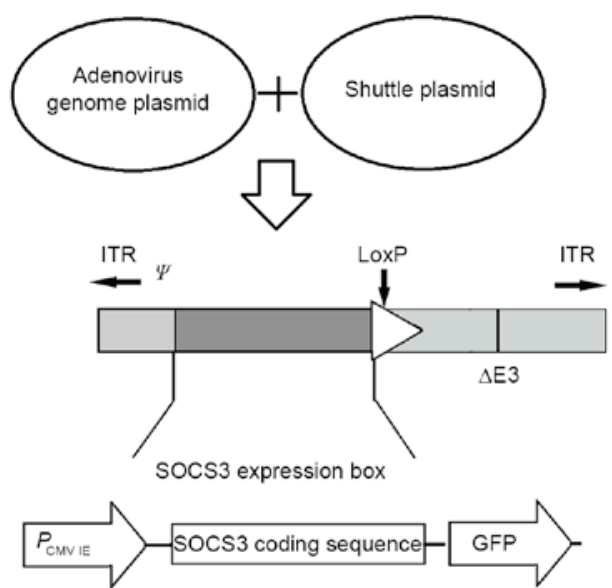

B

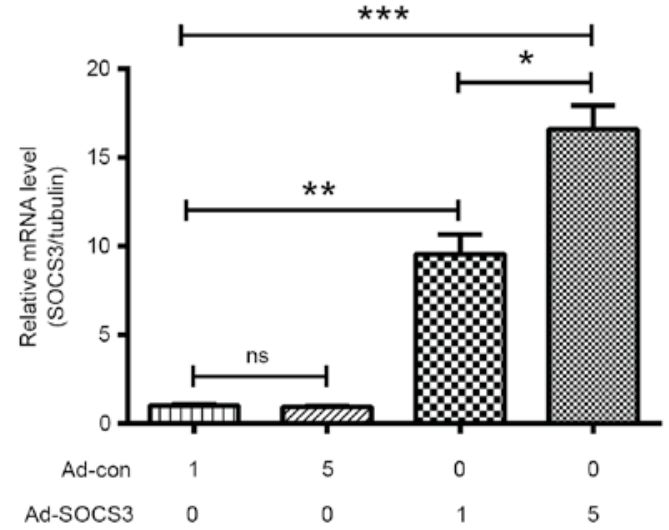

C
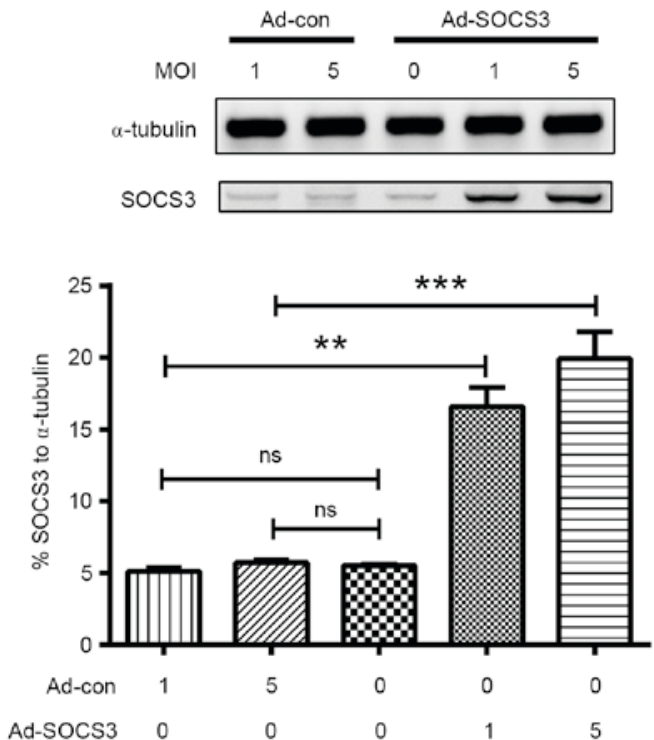

Figure 2. Overexpression of SOCS3 in HK-2 cells via infection with Ad-SOCS3 coding sequence. (A) Diagrammatic sketch of the adenovirus over-expressing SOCS3, with cytomegalovirus immediate early enhancer and promoter as promoter and GFP as a selection marker.(B) Relative mRNA expression levels of SOCS3 to $\alpha$-tubulin in HK-2 cells post-infection with Ad-SOCS3 or Ad-con, with an MOI of 1 or 5 , for 8 h.(C) Upregulated SOCS3 protein expression in HK-2 cells post-infection with Ad-SOCS3 or Ad-con with an MOI of 1 or 5 for $24 \mathrm{~h}$, with $\alpha$-tubulin as internal control. Data are presented as the mean \pm standard error for triple independent results. ${ }^{*} \mathrm{P}<0.05,{ }^{* *} \mathrm{P}<0.01$ or ${ }^{* * *} \mathrm{P}<0.001$; ns, no significance. ITR, inverted terminal repeat; SOCS3, suppressor of cytokine signaling 3; GFP, green fluorescent protein; Ad-con, control adenovirus; Ad-SOCS3, SOCS3-expressing adenovirus; MOI, multiplicity of infection.
A

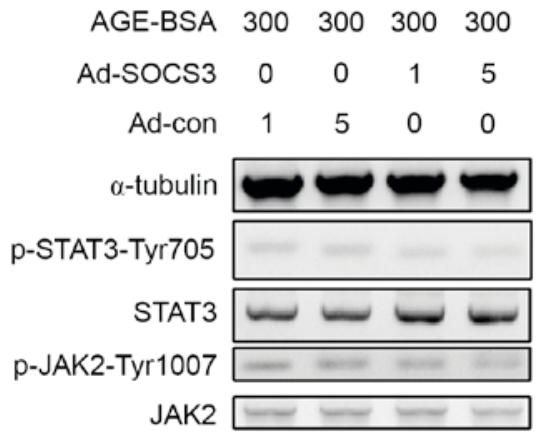

B
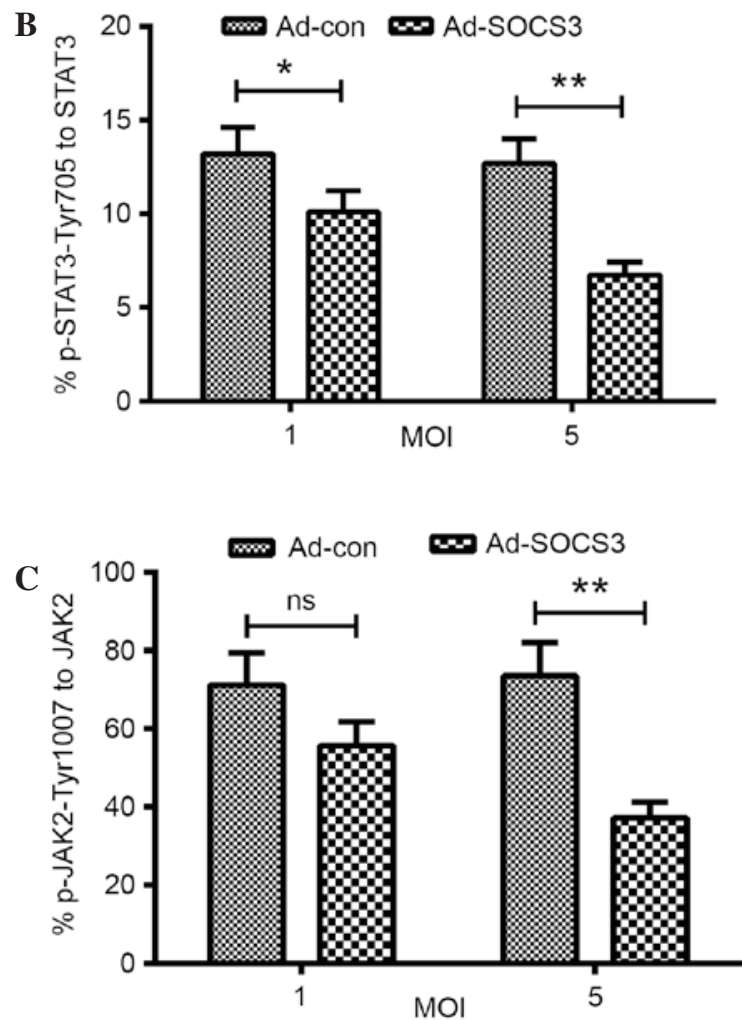

Figure 3. Overexpressed SOCS3 inhibited the promotion by AGE-BSA to JAK/STAT signaling in HK-2 cells. (A) Western blot analysis of phosphorylated JAK2 and STAT3 in the HK-2 cells, which were treated with $300 \mu \mathrm{g} / \mathrm{ml}$ AGE-BSA (for $42 \mathrm{~h}$ ) and infected with Ad-SOCS3 or Ad-con virus with an MOI of 1 or 5 (for 48 h). (B) Percentage of p-STAT3-Tyr705 to total STAT3 in the AGE-BSA-treated and Ad-SOCS3- or Ad-con-infected HK-2 cells. (C) Percentage of p-JAK2-Tyr1007 to total JAK2 in the AGE-BSA-treated and Ad-SOCS3- or Ad-con-infected HK-2 cells. Data are presented as the mean \pm standard error for triple independent results. ${ }^{*} \mathrm{P}<0.05$ and ${ }^{* * *} \mathrm{P}<0.01$; ns, no significance. AGE-BSA; advanced glycation end products-bovine serum albumin; Ad-SOCS3, suppressor of cytokine signaling 3-expressing adenovirus; Ad-Con, control adenovirus; STAT3, signal transducers and activator of transcription 3; JAK2, Janus kinase 2; p-STAT3-Tyr705, STAT3 with a phosphorylated Tyr at 705; p-JAK2-Tyr1007, JAK2 with a phosphorylated Tyr at 1007; MOI, multiplicity of infection.

Adenovirus-mediated overexpression of SOCS3 in HK-2 cells. To further investigate the role of SOCS3 in the AGE-induced EMT in HK-2 cells, we constructed a SOCS3-overexpressing adenovirus. The construction strategy of the recombinant adenovirus overexpressing SOCS3 is presented in Fig. 2A; the Ad-SOCS3 virus was rescued with the plasmid, with the adenoviral genomic sequence and the shuttle plasmid. Then the recombinant virus was rescued following co-transfection with 
A
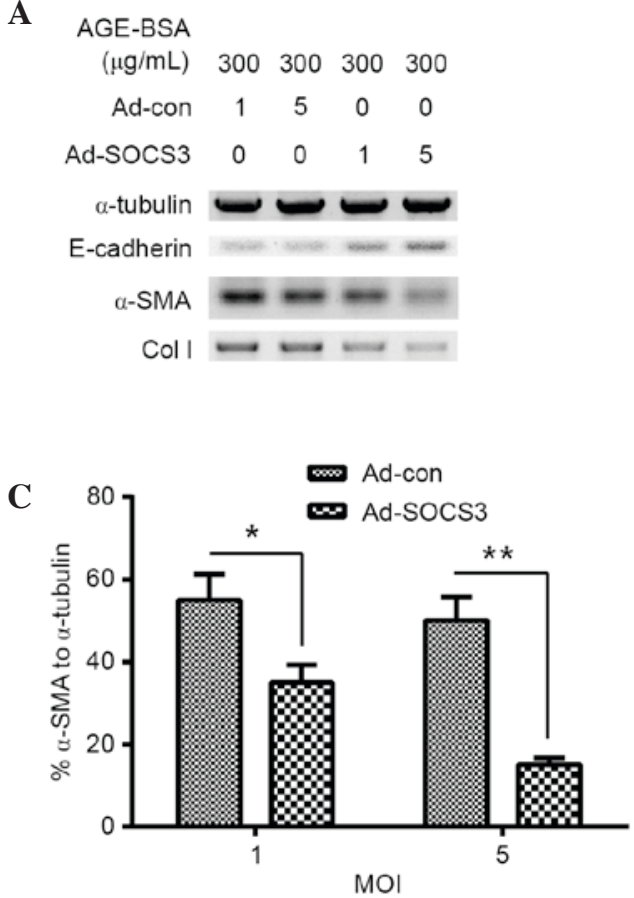
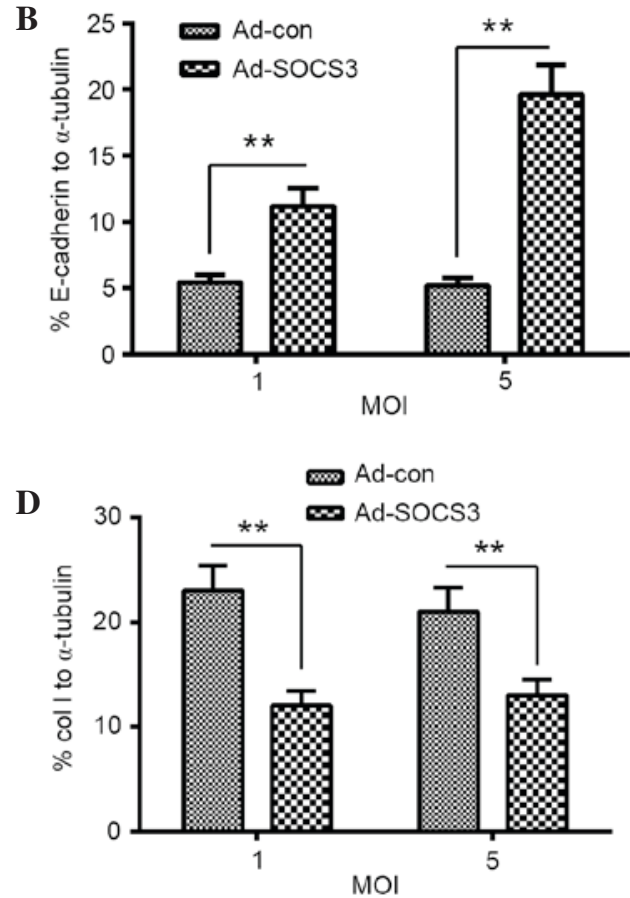

Figure 4. Overexpression of SOCS3 inhibited the promotion of epithelial-to-mesenchymal transition-associated markers by AGE-BSA in HK-2 cells (A) Western blot analysis of E-cadherin, $\alpha$-SMA and col I in the HK-2 cells, which were treated with $300 \mu \mathrm{g} / \mathrm{ml}$ AGE-BSA (for $42 \mathrm{~h}$ ) and infected with Ad-SOCS3 or Ad-con virus with an MOI of 1 or 5 (for 48 h). Percentage of (B) E-cadherin, (C) $\alpha$-SMA or (D) col I to $\alpha$-tubulin in the AGE-BSA-treated and Ad-SOCS3- or Ad-con-infected HK-2 cells. Data are presented as the mean \pm standard error for triple independent results. ${ }^{*} \mathrm{P}<0.05$ and ${ }^{* *} \mathrm{P}<0.01$. AGE-BSA, advanced glycation end products-bovine serum albumin; Ad-con, control adenovirus; Ad-SOCS3, suppressor of cytokine signaling 3-expressing adenovirus; a-SMA; Col I, collagen I; MOI, multiplicity of infection; $\alpha$-SMA, alpha smooth muscle actin.

both plasmids. Analysis of the mRNA and protein expression levels of SOCS3 was performed. Fig. 2B shows that SOCS3 mRNA expression was promoted in the HK-2 cells following infection with 1 or 5 MOI Ad-SOCS3 $(\mathrm{P}<0.01$ or $\mathrm{P}<0.001)$, in a dose-dependent manner $(\mathrm{P}<0.05$; Fig. 2B). Similarly, SOCS3 protein expression was upregulated $>15$ - or $>20$-fold in the 1 or 10 MOI Ad-SOCS3-infected HK-2 cells $(\mathrm{P}<0.01$ or $\mathrm{P}<0.001$; Fig. 2C).

SOCS3 overexpression reduces the JAK/STAT3 activation by $A G E-B S A$. To investigate whether SOCS3 exerts a regulatory role in the AGE-BSA-induced EMT in HK-2 cells, we examined the activation of JAK2/STAT3 signaling by AGE-BSA, in the present infection of Ad-SOCS3 or Ad-con virus. Fig. 3A indicates the detectable phosphorylated STAT3 (p-STAT3-Tyr705) and phosphorylated JAK2 (p-JAK2-Tyr1007) in the HK-2 cells, subject to $300 \mu \mathrm{g} / \mathrm{ml}$ AGE-BSA. Furthermore, the Ad-SOCS3 virus infection significantly reduced the level of p-STAT3-Tyr705; by $\sim 23.48 \%$ for 1 MOI or $\sim 46.93 \%$ for 5 MOI in the Ad-SOCS3 group $(\mathrm{P}<0.05$ or $\mathrm{P}<0.01$; Fig. $3 \mathrm{~A}$ and $\mathrm{B}$ ), compared with the Ad-con group. The expression of p-JAK2-Tyr1007 was also significantly reduced in the HK-2 cells which were infected with 5 MOI Ad-SOCS3 virus $(\mathrm{P}<0.01$; Fig. $3 \mathrm{~A}$ and $\mathrm{C})$. Thus, the present results indicate the inhibitory role of SOCS3 in the JAK2/STAT3 signaling in HK-2 cells, in the presence of AGE-BSA.

SOCS3 overexpression inhibits AGE-BSA-induced EMT in $H K-2$ cells. To further recognize the influence of SOCS3 overexpression on EMT induction by AGE-BSA in HK-2 cells, we re-evaluated the EMT level in the AGE-BSA-treated HK-2 cells, following the infection with Ad-SOCS3 virus or Ad-con virus. Western blot analysis (Fig. 4A) indicated that the Ad-SOCS3 infection of 1 or 5 MOI significantly ameliorated the E-cadherin reduction which was caused by the AGE-BSA treatment with $300 \mu \mathrm{g} / \mathrm{ml}$ (Fig. 4B; either $\mathrm{P}<0.01$ ). By contrast, the upregulated expression of $\alpha$-SMA and collagen $I$ by the $300 \mu \mathrm{g} / \mathrm{ml}$ AGE-BSA was markedly reduced by the Ad-SOCS3 infection with 1 or $5 \mathrm{MOI}$, compared to the Ad-con infection of 1 or 5 MOI (Fig. 4C and D; $\mathrm{P}<0.05$ or $\mathrm{P}<0.01$ ). Therefore, the SOCS3 reduced the AGE-induced EMT in renal TECs.

\section{Discussion}

Proximal tubules reabsorb the plasma proteins and AGEs that are filtered by the glomerulus. The exposure of proximal tubules to the AGEs may lead to pathological tubule injury. In animal models, AGEs injection leads to renal changes similar to those of diabetic nephropathy $(33,34)$. The proceeding of diabetic renal disease by the AGE formation and accumulation suggest the AGEs are involved in the pathogenesis of diabetic nephropathy (35). In the present study, we confirmed that AGE-BSA treatment with $>100 \mu \mathrm{g} / \mathrm{ml}$ significantly promoted the expression of EMT-associated proteins, such as $\alpha$-SMA and collagen I, while significantly reducing the expression of the epithelium-specific molecule E-cadherin in human renal tubule epithelial HK-2 cells.

Diabetic nephropathy (DN) is also recognized as a chronic low-grade inflammatory disease. The innate immune response with promoted proinflammatory cytokines has been 
recognized to serve a crucial function in the pathogenesis and clinical outcome of DN $(36,37)$. However, therapeutic strategies targeting cytokine promotion are effective against DN. The JAK/STAT pathway has been recognized to regulate a variety of genes which are involved in renal inflammation and fibrosis by both of which hyperglycemia contributes to nephropathy associated with diabetes (16,38-40).

Previous experiments have shown that SOCS3, which is one of negative regulators of the JAK/STAT pathway, was induced by hyperglycemia in human and experimental DN renal cells (26). Furthermore, SOCS proteins have been shown to reduce harmful JAK/STAT-mediated cell responses in the diabetic kidney, thus suggesting the potential benefit of SOCS to halt the progression of DN (26). However, the role of promoted SOCS3 in DN is not fully understood; and in particular, it is not clear whether the promoted SOCS3 exerts a regulatory role in the EMT, which is a crucial pathological change in DN (41). The present results confirmed that the adenovirus-mediated SOCS3 overexpression markedly inhibited the AGE-BSA-induced JAK2/STAT3 activation; both p-JAK2 and p-STAT3 were reduced by the Ad-SOCS3 infection, compared to the Ad-con virus infection, in HK-2 cells subject to AGE-BSA. Furthermore, the overexpression of SOCS3 markedly inhibited the AGE-BSA-promoted EMT in HK-2 cells; the AGE-BSA-promoted EMT-associated proteins, such as $\alpha$-SMA and collagen I, were reduced by the Ad-SOCS3 virus infection, in contrast to the Ad-con virus infection, whereas the reduced E-cadherin was reversed by the Ad-SOCS3 virus infection, rather the Ad-con virus infection, in epithelial HK-2 cells.

In summary, the overexpression of SOCS3 reduced the AGE-BSA-induced EMT via inhibiting the JAK2/STAT3 signaling, suggesting a therapeutic effect of SOCS3 overexpression in DN.

\section{Acknowledgements}

The present study was supported by a grant from the National Nature Science Foundation of China (grant no. 81200607).

\section{References}

1. de Boer IH, Rue TC, Hall YN, Heagerty PJ, Weiss NS and Himmelfarb J: Temporal trends in the prevalence of diabetic kidney disease in the United States. JAMA 305: 2532-2539, 2011.

2. Liu ZH: Nephrology in china. Nat Rev Nephrol 9: 523-528, 2013.

3. Gross JL, de Azevedo MJ, Silveiro SP, Canani LH, Caramori ML and Zelmanovitz T: Diabetic nephropathy: Diagnosis, prevention and treatment. Diabetes Care 28 164-176, 2005.

4. Aronson D and Rayfield EJ: How hyperglycemia promotes atherosclerosis: Molecular mechanisms. Cardiovasc Diabetol 1: 1, 2002.

5. Makita Z, Vlassara H, Rayfield E, Cartwright K, Friedman E, Rodby R, Cerami A and Bucala R: Hemoglobin-AGE: A circulating marker of advanced glycosylation. Science 258: 651-653, 1992

6. Brownlee M, Cerami A and Vlassara H: Advanced glycosylation end products in tissue and the biochemical basis of diabetic complications. N Engl J Med 318: 1315-1321, 1988.

7. Makita Z, Radoff S, Rayfield EJ, Yang Z, Skolnik E, Delaney V, Friedman EA, Cerami A and Vlassara H: Advanced glycosylation end products in patients with diabetic nephropathy. $\mathrm{N}$ Engl J Med 325: 836-842, 1991.
8. Yamagishi S, Hsu CC, Taniguchi M, Harada S, Yamamoto Y, Ohsawa K, Kobayashi K and Yamamoto H: Receptor-mediated toxicity to pericytes of advanced glycosylation end products: A possible mechanism of pericyte loss in diabetic microangiopathy. Biochem Biophys Res Commun 213: 681-687, 1995.

9. Goldin A, Beckman JA, Schmidt AM and Creager MA: Advanced glycation end products: Sparking the development of diabetic vascular injury. Circulation 114: 597-605, 2006.

10. Denis U, Lecomte M, Paget C, Ruggiero D, Wiernsperger N and Lagarde M: Advanced glycation end-products induce apoptosis of bovine retinal pericytes in culture: Involvement of diacylglycerol/ceramide production and oxidative stress induction. Free Radic Biol Med 33: 236-247, 2002.

11. Min C, Kang E, Yu SH, Shinn SH and Kim YS: Advanced glycation end products induce apoptosis and procoagulant activity in cultured human umbilical vein endothelial cells. Diabetes Res Clin Pract 46: 197-202, 1999.

12. Liu JP, Feng L, Zhu MM, Wang RS, Zhang MH, Hu SY, Jia XB and $\mathrm{Wu} J \mathrm{~J}$ : The in vitro protective effects of curcumin and demethoxycurcumin in Curcuma longa extract on advanced glycation end products-induced mesangial cell apoptosis and oxidative stress. Planta Med 78: 1757-1760, 2012.

13. Burns WC, Twigg SM, Forbes JM, Pete J, Tikellis C, Thallas-Bonke V, Thomas MC, Cooper ME and Kantharidis P: Connective tissue growth factor plays an important role in advanced glycation end product-induced tubular epithelial-to-mesenchymal transition: Implications for diabetic renal disease. J Am Soc Nephrol 17: 2484-2494, 2006.

14. Liu Y: Epithelial to mesenchymal transition in renal fibrogenesis: Pathologic significance, molecular mechanism, and therapeutic intervention. J Am Soc Nephrol 15: 1-12, 2004.

15. Brosius FR III and Banes-Berceli A: A new pair of SOCS for diabetic nephropathy. J Am Soc Nephrol 21: 723-724, 2010.

16. Marrero MB, Banes-Berceli AK, Stern DM and Eaton DC: Role of the JAK/STAT signaling pathway in diabetic nephropathy. Am J Physiol Renal Physiol 290: F762-F768, 2006.

17. Banes-Berceli AK, Shaw S, Ma G, Brands M, Eaton DC, Stern DM, Fulton D, Caldwell RW and Marrero MB: Effect of simvastatin on high glucose- and angiotensin II-induced activation of the JAK/STAT pathway in mesangial cells. Am J Physiol Renal Physiol 291: F116-F121, 2006.

18. Huang JS, Guh JY, Hung WC, Yang ML, Lai YH, Chen HC and Chuang LY: Role of the Janus kinase (JAK)/signal transducters and activators of transcription (STAT) cascade in advanced glycation end-product-induced cellular mitogenesis in NRK-49F cells. Biochem J 342: 231-238, 1999.

19. Twigg SM, Cao Z, MCLennan SV, Burns WC, Brammar G, Forbes JM and Cooper ME: Renal connective tissue growth factor induction in experimental diabetes is prevented by aminoguanidine. Endocrinology 143: 4907-4915, 2002.

20. Gilbert RE, Akdeniz A, Weitz S, Usinger WR, Molineaux C, Jones SE, Langham RG and Jerums G: Urinary connective tissue growth factor excretion in patients with type 1 diabetes and nephropathy. Diabetes Care 26: 2632-2636, 2003.

21. Kanwar YS, Wada J, Sun L, Xie P, Wallner EI, Chen S, Chugh S and Danesh FR: Diabetic nephropathy: Mechanisms of renal disease progression. Exp Biol Med (Maywood) 233: 4-11, 2008.

22. Zeisberg $M$ and Kalluri R: Fibroblasts emerge via epithelial-mesenchymal transition in chronic kidney fibrosis. Front Biosci 13: 6991-6998, 2008.

23. Conway B and Hughes J: Cellular orchestrators of renal fibrosis. QJM 105: 611-615, 2012.

24. Wang X, Shaw S, Amiri F, Eaton DC and Marrero MB: Inhibition of the Jak/STAT signaling pathway prevents the high glucose-induced increase in tgf-beta and fibronectin synthesis in mesangial cells. Diabetes 51: 3505-3509, 2002.

25. Tsai KD, Chen W, Wang SH, Hsiao YW, Chi JY, Wu HY, Lee YJ, Wong HY, Tseng MJ and Lin TH: Downregulation of connective tissue growth factor by LPS/IFN- $\gamma$-induced nitric oxide is reversed by aristolochic acid treatment in glomerular mesangial cells via STAT- $1 \alpha$ and NF- $\mathrm{B}$ signaling. Chem Biol Interact 210: 86-95, 2014.

26. Ortiz-Munoz G, Lopez-Parra V, Lopez-Franco O, Fernandez-Vizarra P, Mallavia B, Flores C, Sanz A, Blanco J, Mezzano S, Ortiz A, et al: Suppressors of cytokine signaling abrogate diabetic nephropathy. J Am Soc Nephrol 21: 763-772, 2010 .

27. Babon JJ, Lucet IS, Murphy JM, Nicola NA and Varghese LN: The molecular regulation of Janus kinase (JAK) activation. Biochem J 462: 1-13, 2014. 
28. Berthier CC, Zhang H, Schin M, Henger A, Nelson RG, Yee B, Boucherot A, Neusser MA, Cohen CD, Carter-Su C, et al: Enhanced expression of Janus kinase-signal transducer and activator of transcription pathway members in human diabetic nephropathy. Diabetes 58: 469-477, 2009.

29. Takeuchi M, Bucala R, Suzuki T, Ohkubo T, Yamazaki M, Koike T, Kameda Y and Makita Z: Neurotoxicity of advanced glycation end-products for cultured cortical neurons. J Neuropathol Exp Neurol 59: 1094-1105, 2000.

30. Hammes HP, Wellensiek B, Klöting I, Sickel E, Bretzel RG and Brownlee M: The relationship of glycaemic level to advanced glycation end-product (AGE) accumulation and retinal pathology in the spontaneous diabetic hamster. Diabetologia 41: 165-170, 1998.

31. Livak KJ and Schmittgen TD: Analysis of relative gene expression data using real-time quantitative PCR and the 2(-Delta Delta C (T)) Method. Methods 25: 402-408, 2001.

32. He TC, Zhou S, da Costa LT, Yu J, Kinzler KW and Vogelstein B A simplified system for generating recombinant adenoviruses. Proc Natl Acad Sci USA 95: 2509-2514, 1998.

33. Vlassara H, Striker LJ, Teichberg S, Fuh H, Li YM and Steffes M: Advanced glycation end products induce glomerular sclerosis and albuminuria in normal rats. Proc Natl Acad Sci USA 91: 11704-11708, 1994.

34. Brownlee M, Vlassara H, Kooney A, Ulrich P and Cerami A: Aminoguanidine prevents diabetes-induced arterial wall protein cross-linking. Science 232: 1629-1632, 1986.

35. Beisswenger PJ, Makita Z, Curphey TJ, Moore LL, Jean S, Brinck-Johnsen T, Bucala R and Vlassara H: Formation of immunochemical advanced glycosylation end products precedes and correlates with early manifestations of renal and retinal disease in diabetes. Diabetes 44: 824-829, 1995.
36. Gupta S, Mehndiratta M, Kalra S, Kalra OP, Shukla R and Gambhir JK: Association of tumor necrosis factor (TNF) promoter polymorphisms with plasma TNF- $\alpha$ levels and susceptibility to diabetic nephropathy in North Indian population. J Diabetes Complications 29: 338-342, 2015.

37. Lee SH, Lee TW, Ihm CG, Kim MJ, Woo JT and Chung JH: Genetics of diabetic nephropathy in type 2 DM: Candidate gene analysis for the pathogenic role of inflammation. Nephrology (Carlton) 10 (Suppl): S32-S36, 2005

38. Ortiz-Muñoz G, Lopez-Parra V, Lopez-Franco O, Fernandez-Vizarra P, Mallavia B, Flores C, Sanz A, Blanco J, Mezzano S, Ortiz A, et al: Suppressors of cytokine signaling abrogate diabetic nephropathy. J Am Soc Nephrol 21: 763-772, 2010.

39. Nangaku M: Mechanisms of tubulointerstitial injury in the kidney: Final common pathways to end-stage renal failure. Intern Med 43: 9-17, 2004.

40. Lu TC, Wang ZH, Feng X, Chuang PY, Fang W, Shen Y, Levy DE, Xiong H, Chen N and He JC: Knockdown of Stat3 activity in vivo prevents diabetic glomerulopathy. Kidney Int 76 : 63-71, 2009.

41. Habib SL: Alterations in tubular epithelial cells in diabetic nephropathy. J Nephrol 26: 865-869, 2013. 